was also emphasised that the ratio of bases is not a constant for a given soil but varies with the water content, especially with respect to potassium. Moreover, the ratio on which bases are absorbed would appear to be itself dependent on the hydrogen-ion concentration. Experiments in which the proportion of potassium was increased had shown an increase of lime-loving species.

Dr. N. M. Comber considered chiefly the "sourness " of certain agricultural soils and their characteristics. The cause of "sourness" could not be the hydrogen-ion concentration, since this is sometimes high when " sourness," as measured by the character of the crop, is absent. Nor was it merely the ratio of calcium to other metals (e.g. potassium and sodium), since the addition of neutral calcium does not decrease the sourness, and the addition of potassium salts does not enhance it. He indicated the evidence that the ratio of basic lime to weak bases (chiefly alumina) was a fundamental cause of sourness.

Dr. W. H. Pearsall simplified the problem by considering the growth and distribution of aquatic organisms such as green algæ and diatoms, and pointed out that the former or latter predominated according as to whether the ratio $\frac{\mathrm{K}+\mathrm{Na}}{\mathrm{Ca}}$ was high or low. He gave details of water culture experiments in which Eriophorum and Sphagnum both grew rapidly with high basic ratios (in the absence of alumina) whether the $\mathrm{P}_{\mathrm{H}}$ was 4.5 or 7 . He stated that heath plants have a high fat concentration which is chiefly affected by the basic ratio.

Prof. J. H. Priestley indicated that the relative proportion of certain bases in the soil materially affected the migration of fatty substances along the cell walls. As a consequence the deposition of fat might be considerably modified by the bases in the soils. Plants forming unusually' large quantities of fatty acids, such as those characteristic of peaty habitats, might be disorganised when grown on soils containing more calcium, as the result of the choking of the tissue immediately behind the meristem through the accumulation of calcium soaps. From this point of view the important " basic ratio" in the soil was the proportion of $\mathrm{K}+\mathrm{Na}+\mathrm{Mg}$ to $\mathrm{Ca}$.

Prof. D. R. Hoagland, of California, referred to the importance of studying the actual soil solution, means for which had now been devised, and emphasised the fact that the results so far obtained indicated a varying basic ratio with changing water content. All common agricultural plants had been grown in water cultures at a $\mathrm{P}_{\mathrm{m}}$ of 4.8 although plants have great power of reducing the hydroxyl-ion concentration.

Dr. W. R. G. Atkins disagreed with Dr. Salisbury about the two optimum $\mathrm{P}_{\mathrm{H}}$ values for the distribution of certain plants, and suggested that exceptions in the distribution of desmids and diatoms might indicate the existence of other controlling factors than that of basic ratios.

Dr. Joseph, of Khartoum, spoke of the highly alkaline soils of Egypt, and stressed the point that no mention of the importance of the physical condition of the soil had been made during the discussion.

Dr. M. C. Rayner said that in Calluna vulgaris the hydrogen-ion concentration was not a critical factor since it could be grown in a solution of $P_{H} 8$.

Dr. H. Jeffreys emphasised the need for detailed field observation of plant distribution, and the importance of the competition factor.

Dr. Salisbury briefly replied to some of the issues which had been raised.

\title{
Annual Meeting of the Association of Women Science Teachers.
}

THE annual meeting of the Association of Women Science Teachers was held on Saturday, January 26, at University College, London. At the business meeting a resolution was passed unanimously, in the following terms :

"The A.W.S.T. feels that the need for a course of training for intending teachers of science is very great, and fully realises that the problems and difficulties confronting them are different from those obtaining in other subjects. The Association therefore suggests that to meet the need it is important that greater facilities for practical work, and more specialised training in the organising and manipulative side of science teaching, should be given in many of the Secondary Training Colleges."

It was stated that very few science teachers have been trained, and this is in part due to the fact that very little special consideration is given to their work at the Training Colleges, and that therefore the course is of less use to them than to Arts students.

It seems to be the experience of most senior science mistresses in Secondary Schools that the junior mistresses who come to them straight from the Universities have no experience of the type of experiment with which they have to cope in school, and that therefore their whole attention has to be given to the manipulative work, and none is left for the class. This is obviously an undesirable state of affairs, and it was urged that science students at Training Colleges should have considerable practice in the actual performance of experiments, and to a less extent in the improvising of apparatus, either in the laboratories of the Training Colleges, or, where such do not exist, in a good Secondary School. In the latter case the practice should be continuous for some weeks, in order to give the student an idea of laboratory management, and the planning out of the contents of a syllabus.

Mr. C. A. Carus-Wilson then delivered an address on a new method of approaching the general elementary science which normally precedes the more specialised study of physics and chemistry. The main points of his contention are (I) that the present method is too academic for junior classes, and tends to be very limited in scope; (2) that by considering the properties of well-known substances the child is given something which can be linked on to his everyday life. The study of the properties of different materials, such as hardness, toughness, elasticity, the relative heaviness (without accurate weighing), the relative fusibility of metals, the changes in property induced by heat, would give a very good general idea of heat and mechanics on which formal physics and chemistry could later be built. If, on the other hand, the child does not proceed any further than the general course, he will have a far more intelligent idea of the world about him than is given by the usual study of relative densities, thermometers, etc.

In the afternoon, Dr. G. L. Elles gave a lecture on "The Scientific Interpretation of Scenery." She said that the science of geomorphology recognises that two factors are at work in the evolution of sceneryone constructive and resulting in the building up of mountains, the other destructive and tending to reduce everything eventually to a uniform level. The former includes volcanic action and other internal factors of change in the earth's surface. The destructive forces of denudation include weathering and transport of the broken-down material. Erosion is of different types according as it is carried on by water, ice, or dry sand driven by the wind. 